\title{
Outcomes of the surgical management of encapsulating peritoneal sclerosis: A case series from a single center in Korea
}

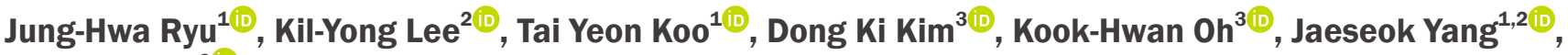 \\ Kyu Joo Park ${ }^{2}$ iD \\ 'Transplantation Center, Seoul National University Hospital, Seoul, Republic of Korea \\ ²Department of Surgery, Seoul National University Hospital, Seoul, Republic of Korea \\ ${ }^{3}$ Department of Internal Medicine, Seoul National University College of Medicine, Seoul, Republic of Korea
}

\begin{abstract}
Background: Encapsulating peritoneal sclerosis (EPS) is a rare but near-fatal complication of peritoneal dialysis (PD). Despite the high mortality rate of EPS, the surgical treatment strategy of severe EPS is yet to be established.

Methods: We retrospectively analyzed outcomes of patients with EPS who underwent enterolysis for intractable EPS at Seoul National University Hospital between 2001 and 2018. EPS was diagnosed based on the clinical symptoms and radiological findings of abdominal computed tomography (CT). CT scans were scored according to an EPS scoring system that assessed peritoneal thickening and calcification as well as bowel thickening, tethering, loculation, and dilatation.

Results: Thirteen patients (nine males and four females; age, 48 [29-63] years) underwent enterolysis for severe EPS. PD duration (11 [6-21] years) was not associated with survival. Two patients were newly diagnosed with EPS following kidney transplantation. Five patients died of infectious complications immediately after the surgery. Eight patients survived after the first surgery; however, five of them underwent reoperation but died of persistent infection, fistula formation, or adhesive bowel obstruction. Four young $(<60$ years) male patients with relatively low CT scan scores $(<13)$ survived for $>2$ years after the first surgery. Median survival duration from EPS diagnosis was 22 (1.3184) months and that from the first surgery was 9 (0.3-153) months.

Conclusion: The high mortality rate of EPS suggests the importance of appropriate surgical intervention in young symptomatic male EPS patients with relatively low CT scan scores.
\end{abstract}

Keywords: Encapsulating peritoneal sclerosis, Mortality, Peritoneal dialysis, Surgery

Received April 18, 2019; Revised August 21, 2019;

Accepted September 4, 2019

Edited by Cheol Whee Park, The Catholic University of Korea,

Seoul, Republic of Korea

Correspondence: Jaeseok Yang

Transplantation Center, Department of Surgery, Seoul National University Hospital, 101 Daehak-ro, Jongno-gu, Seoul 03080, Republic of Korea.E-mail: jcyjs@snu.ac.kr

Copyright (C) 2019 by The Korean Society of Nephrology

(a) This is an open-access article distributed under the terms of the Creative Commons Attribution Non-Commercial License (http://creativecommons. org/licenses/by-nc-nd/4.0/), which permits unrestricted non-commercial use, distribution, and reproduction in any medium, provided the original work is properly cited.

\section{Introduction}

Peritoneal dialysis (PD) is a standard therapy for endstage renal disease (ESRD) [1]. PD shows several benefits, such as low annual medical costs, survival advantage over in-center hemodialysis in the early stage, and improved quality of life in terms of the convenience of home care [2]. However, with increased cumulative duration of $\mathrm{PD}$, undesirable long-term complications, such as recurrent peritonitis, dialysis failure, and peritoneal sclerosis, develop. 
Although very rare, encapsulating peritoneal sclerosis (EPS) is the most severe complication of long-term PD $[3,4]$. EPS is a syndrome that repeatedly manifests with partial or complete intestinal obstruction caused by encapsulating fibrotic tissues forming a cocoon-like structure with diffuse peritoneal thickening and calcification [5-7]. EPS in PD patients is a progressive disease with chronic intra-abdominal inflammation triggered by the iatrogenic PD solution. Symptomatic EPS often leads to PD discontinuation; however, it typically manifests after transfer to hemodialysis or kidney transplantation $[6,8,9]$. Clinically, this syndrome is characterized by obstructive symptoms, such as nausea, vomiting, abdominal pain, and malnutrition due to poor oral intake. These symptoms usually progress insidiously, and full-blown symptoms from bowel obstruction result in malnutrition and poor quality of life.

The overall incidence of EPS in the PD population is between $0.5 \%$ and $7.5 \%$ [8-13], which increases proportionally with PD duration, particularly of $>5$ years. A prospective Japanese study reported that a $0 \%$ incidence of EPS 3 years after PD initiation increased to up to $17.2 \%$ after 15 years [8]. Once symptomatic EPS is diagnosed, the prognosis is substantially poor, with the mortality rate being up to $55 \%$ in the first year after diagnosis [13].

The pathophysiological mechanism underlying PDassociated EPS is explained by the "two-hit hypothesis" $[10,13,14]$. The first hit is triggered by predisposing factors such as PD initiation and repeated peritoneal exposure to the PD solution. Repeated PD cycles deteriorate peritoneal inflammation, fibrosis, and diffuse sclerosis. The second hit includes bacterial peritonitis, recurrent peritonitis, excessive peritoneal fibrogenetic reaction to the PD solution (which promotes transforming growth factor- $\beta 1$ signaling cascades [15]), and elevated collagenosis and fibrogenesis [16].

Desperate therapeutic options have been employed to reverse the deteriorated clinical outcomes of EPS. Timely and early administration of steroids and tamoxifen before the development of advanced malnutrition and symptomatic EPS reduces intraperitoneal inflammation and ascites and relieves bowel obstructive symptoms $[8,17,18]$. However, although reports of successful therapeutic experiences in advanced EPS are relatively limited, successful surgical treatment of advanced EPS has been reported. Kawanishi et al [19] described 17 years of experience of surgical interventions for EPS and reported favorable outcomes in 181 of the 239 surgical treatments. Ulmer et al [20] reported successful surgical outcomes in $37 \%$ of the 45 EPS patients. However, a treatment strategy for the surgical management of severe EPS has not been established. Therefore, in this study, we aimed to describe our surgical experiences of advanced EPS in a single center in Korea.

\section{Methods}

\section{Patients}

From January 2001 to December 2018, 21 patients were diagnosed with EPS at Seoul National University Hospital. Thirteen patients underwent surgical intervention for intractable EPS. Surgery was considered for EPS treatment in patients who met any of the following conditions: development of intractable obstructive symptoms refractory to medication and conservative treatment, severe malnutrition despite long-term total parenteral nutrition, postprandial vomiting, and severe abdominal pain due to bowel obstruction, as documented by small bowel series or computed tomography (CT). All surgeries were performed by the same surgeon without a major change in the technique. We defined the initial mortality group as the deceased patients after the first EPS surgery and the initial survivor group as the survived patients after the 1st surgery.

All patients presented a history of PD preoperatively. EPS was diagnosed based on the guidelines proposed by the International Society for PD (ISPD) [5]. All patients presented with bowel obstructive symptoms, and contrast-enhanced abdominal CT confirmed encapsulated intestine and peritoneal and bowel wall thickening. The study was conducted in accordance with the Declaration of Helsinki, and the study protocol was approved by the Institutional Review Board (IRB) of Seoul National University Hospital (approval number: H-1901-156-1006). The written informed consent from the participants for this retrospective study was waived by IRB.

\section{Data collection}

Patient data were retrospectively collected from the hospital's electronic medical records. Demographic char- 
acteristics included age, sex, body mass index, primary ESRD cause, PD duration, PD discontinuation cause, and cumulative number of peritonitis episodes. Clinical symptoms related to EPS; laboratory findings during the perioperative period (serum albumin, hemoglobin, Creactive protein, total calcium, and phosphorus levels); and cultured organisms during the individual episodes of peritonitis were reviewed. Moreover, CT findings, surgical records, postoperative progress, and outcomes were evaluated. CT scans were examined by experienced radiologists. CT scan scores were calculated according to a previously published scoring system [21]. Briefly, EPS progression was evaluated based on six scoring parameters: peritoneal thickening and calcification as well as bowel wall thickening, tethering, loculation, and dilatation. Each parameter was scored from 0 to 4 points $(0-3$ points for bowel tethering and loculation) according to pathological changes (Supplementary Table 1, available online) [21]. Bowel tethering was defined as an abrupt change in bowel caliber caused by severe fibrosis.

\section{Results}

\section{Patient characteristics}

Of the 21 patients diagnosed as having EPS, eight did not undergo surgical treatment. Of the eight, five patients presented with mild EPS symptoms, such as dyspepsia, decreased oral intake, and constipation, and they did not show severe obstructive symptoms requiring total parenteral nutrition. Among the five patients, kidney transplantation was performed in one and dialysis modality was changed to hemodialysis in four; however, one patient died of peritonitis-associated sepsis.

Thirteen patients (nine males and four females) underwent surgical treatment, and their baseline characteristics are described in Table 1. Median patient age was 48 (29-63) years. The underlying cause of renal disease was glomerulonephritis in five patients, hypertension in three, and other disorders in five; no patient had diabetes. Median PD duration was $11(6-21)$ years. The most common cause of PD withdrawal was bacterial peritonitis (46.1\%), followed by EPS (30.8\%) and kidney transplantation (23.1\%). Mean body mass index was $19.3 \pm 2.4 \mathrm{~kg} / \mathrm{m}^{2}$; mean serum albumin level was $3.1 \pm 0.5 \mathrm{~g} / \mathrm{dL}$; and mean hemoglobin level was $10.1 \pm 1.4 \mathrm{~g} / \mathrm{dL}$ (Table 2). Pathogens were detected during prior episodes of peritonitis in most patients, with Enterococcus faecium being the most common pathogen.

Table 1. Clinical characteristics of study subjects and EPS

\begin{tabular}{|c|c|c|c|c|c|c|c|c|}
\hline Patients & Age (yr) & Sex & $\begin{array}{c}\text { Underlying } \\
\text { renal disease }\end{array}$ & $\begin{array}{c}\text { PD duration } \\
(\mathrm{yr})\end{array}$ & $\begin{array}{l}\text { Reason for PD } \\
\text { discontinuation }\end{array}$ & $\begin{array}{c}\text { Peritonitis } \\
\text { episode number }\end{array}$ & $\begin{array}{l}\text { Onset of EPS from } \\
\text { PD withdrawal (mo) }\end{array}$ & $\begin{array}{c}\text { Clinical } \\
\text { symptoms }\end{array}$ \\
\hline 1 & 48 & Female & Hypertension & 6 & Peritonitis & 1 & 1 & $\mathrm{P}, \mathrm{F}$ \\
\hline 2 & 42 & Male & IgA nephropathy & 21 & Peritonitis & 2 & 1 & $\mathrm{~N}, \mathrm{~V}, \mathrm{P}$ \\
\hline 3 & 54 & Female & Unknown & 6 & Peritonitis & 3 & 156 & $\mathrm{~N}, \mathrm{~V}, \mathrm{P}$ \\
\hline 4 & 63 & Male & Hypertension & 11 & Peritonitis & 2 & $-21^{a}$ & $\mathrm{~N}, \mathrm{~V}, \mathrm{P}, \mathrm{F}$ \\
\hline 5 & 51 & Male & Unknown & 18 & EPS & 5 & $-1^{\mathrm{a}}$ & $\mathrm{N}, \mathrm{V}, \mathrm{P}$ \\
\hline 6 & 54 & Male & HBGN & 16 & KT & 1 & 48 & $\mathrm{~N}, \mathrm{~V}, \mathrm{P}, \mathrm{F}$ \\
\hline 7 & 48 & Female & GN & 12 & KT & $>1$ & 18 & $\mathrm{~N}, \mathrm{~V}, \mathrm{P}, \mathrm{F}, \mathrm{C}$ \\
\hline 8 & 50 & Male & Trauma & 16 & EPS & 0 & 2 & $\begin{array}{l}\text { N/abdominal } \\
\text { fullness }\end{array}$ \\
\hline 9 & 43 & Female & Hypertension & 7 & Peritonitis & $>1$ & 36 & $\mathrm{~N}, \mathrm{~V}, \mathrm{P}$ \\
\hline 10 & 42 & Male & ADPKD & 11 & EPS & 1 & $-11^{a}$ & $\mathrm{~N}, \mathrm{~V}$ \\
\hline 11 & 38 & Male & GN & 10 & KT & 0 & $-3^{a}$ & $\mathrm{~N}, \mathrm{~V}, \mathrm{P}, \mathrm{F}$ \\
\hline 12 & 58 & Male & Unknown & 8 & EPS & 0 & 2 & $\mathrm{~A}, \mathrm{~N}, \mathrm{~F}$ \\
\hline 13 & 29 & Male & FSGS & 9 & Peritonitis & 7 & 20 & $\mathrm{~N}, \mathrm{P}$ \\
\hline
\end{tabular}

ADPKD, autosomal dominant polycystic kidney disease; C, constipation; EPS, encapsulating peritoneal sclerosis; F, fever; FSGS, focal segment glomerulosclerosis; GN, glomerulonephritis; HBGN, hepatitis B-associated glomerulonephritis; KT, kidney transplantation; N, nausea; P, pain; PD, peritoneal dialysis; V, vomiting. ${ }^{a}$ Negative values indicate that EPS was diagnosed prior to PD discontinuation. 


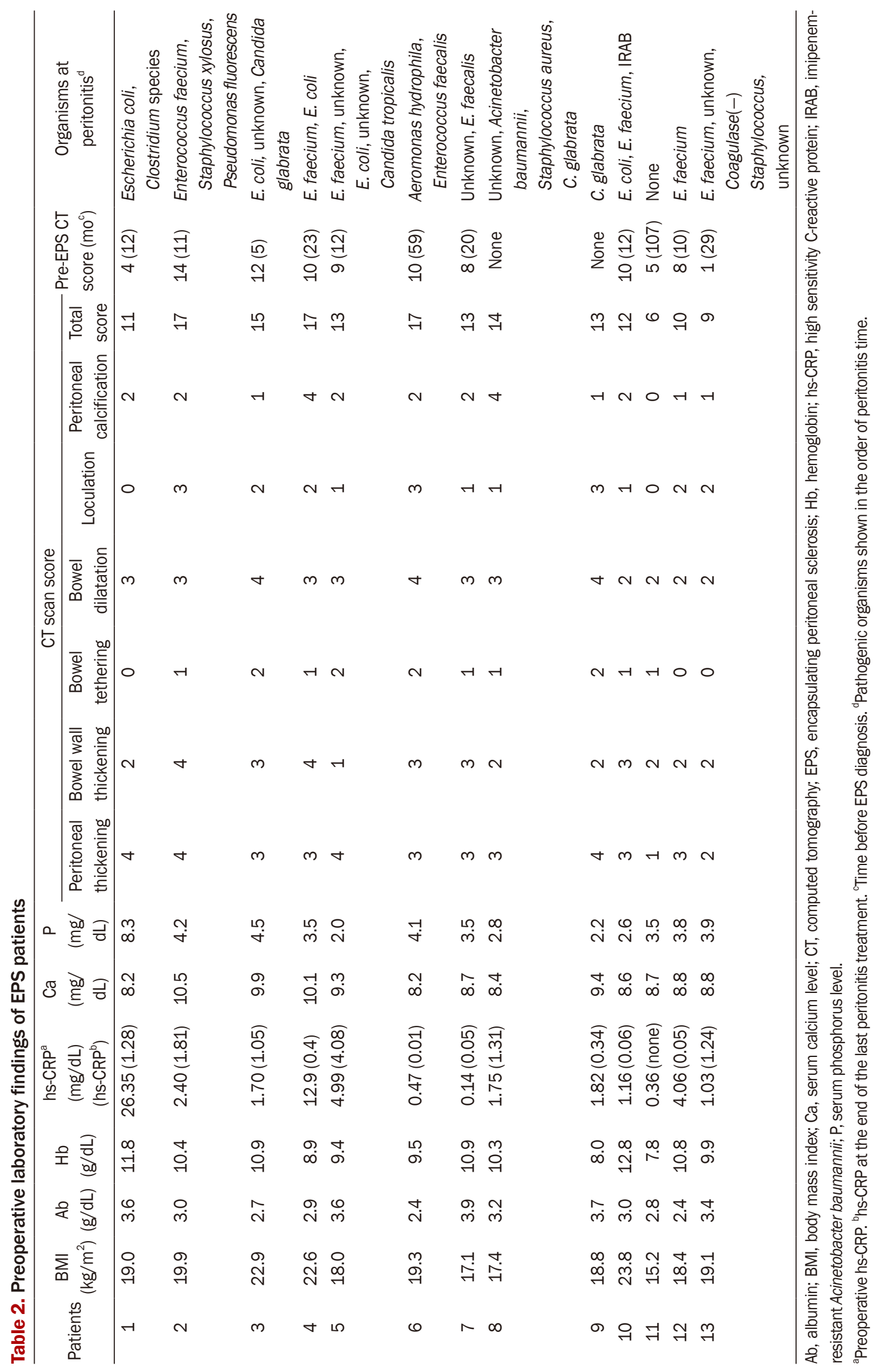




\section{Characteristics of EPS and surgical treatment}

Most patients with EPS were diagnosed after PD discontinuation, and the median time from EPS development to surgery was $8(0-31)$ months. All patients presented with severe obstructive symptoms (nausea, vomiting, and abdominal pain). Although some patients received total parenteral nutritional support, their symptoms and malnutrition did not improve. All patients underwent enterolysis or adhesiolysis as the first surgical intervention. However, some patients who required a second adhesiolysis underwent additive procedures. Case 2 underwent colostomy due to bowel perforation, case 5 under- went small bowel resection, case 6 underwent transverse colon resection, and case 8 underwent jejunostomy. Intraoperative and radiological findings before and after enterolysis are shown in Fig. 1. Abdominal CT scans of the EPS patients are shown in Fig. 2, demonstrating diffusely thickened and calcified peritoneal wall, dilated and thickened bowel loops, and loculated ascites. Table 2 summarizes the total CT scan scores. The median total CT score was 14 (6-17) (Table 2). The histologic finding of adhesiolysed peritoneum showed thickened peritoneal membrane, chronic inflammation, massive peritoneal fibrosis, and calcification (Fig. 3).
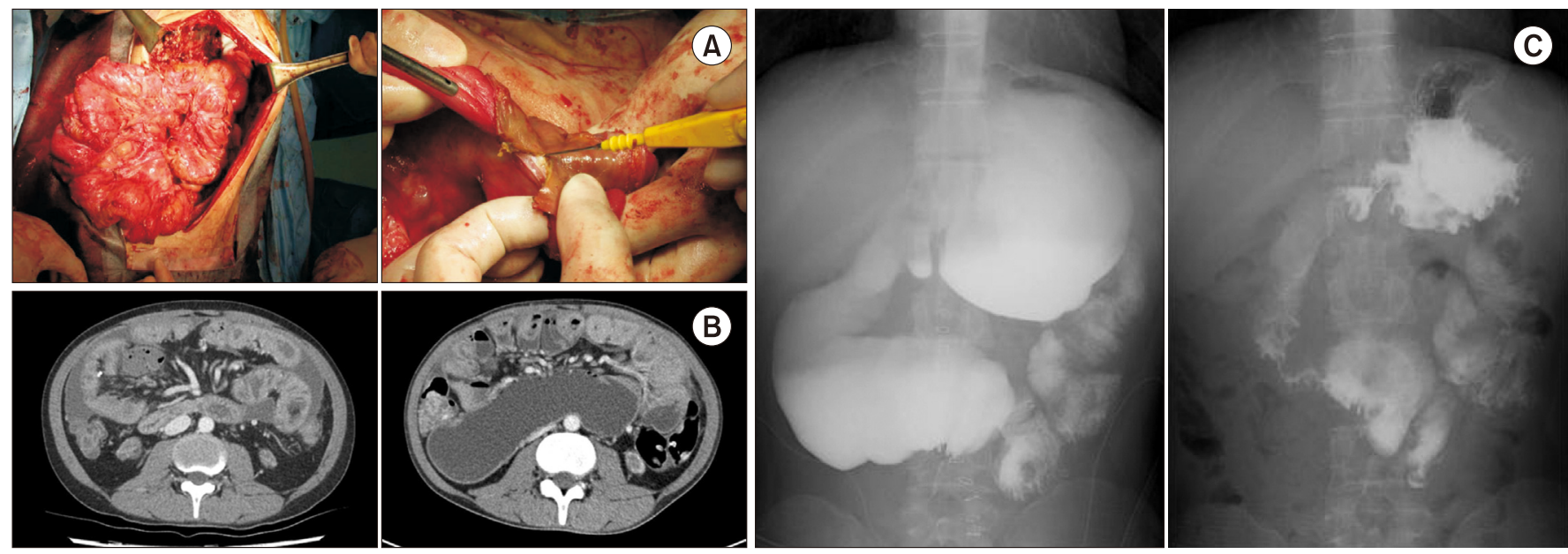

Figure 1. Intraoperative and radiological findings of encapsulating peritoneal sclerosis. (A) The clumped intestine was covered with dense fibrosclerotic materials forming a cocoon-like structure (left). The dense, thick fibrotic cover was incised using a sharp knife during enterolysis (right). (B) Abdominal computed tomography showed thickened peritoneal and bowel walls, dilated and thickened bowel loops, and loculated ascites. (C) Small bowel series with gastrografin showed partial obstruction and delayed emptying of the small bowel from the stomach (left). However, this obstruction was released after laparotomy and adhesiolysis (right).
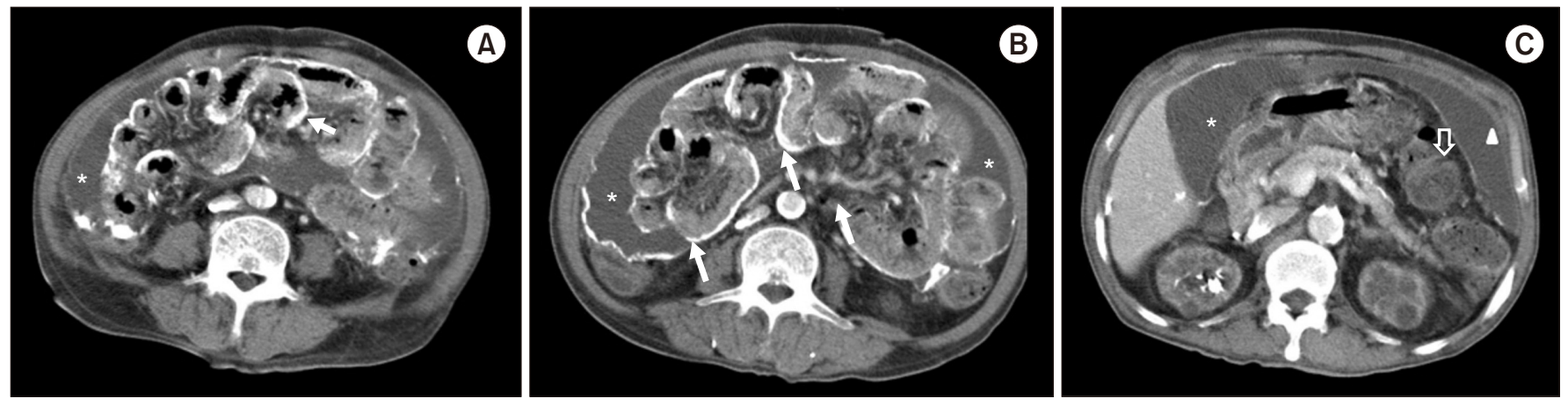

Figure 2. Contrast-enhanced computed tomography (CT) findings of advanced encapsulating peritoneal sclerosis. Diffuse peritoneal calcification (filled arrows) and dilated and thickened bowel loops were noted on CT of Patient 1 (A) and Patient 10 (B). The thickened bowel wall and loculated ascites were also noted (asterisks). (C) Thickened peritoneal wall (arrowhead) and thickened bowel wall enclosed by the peritoneum (empty arrow) were noted. 

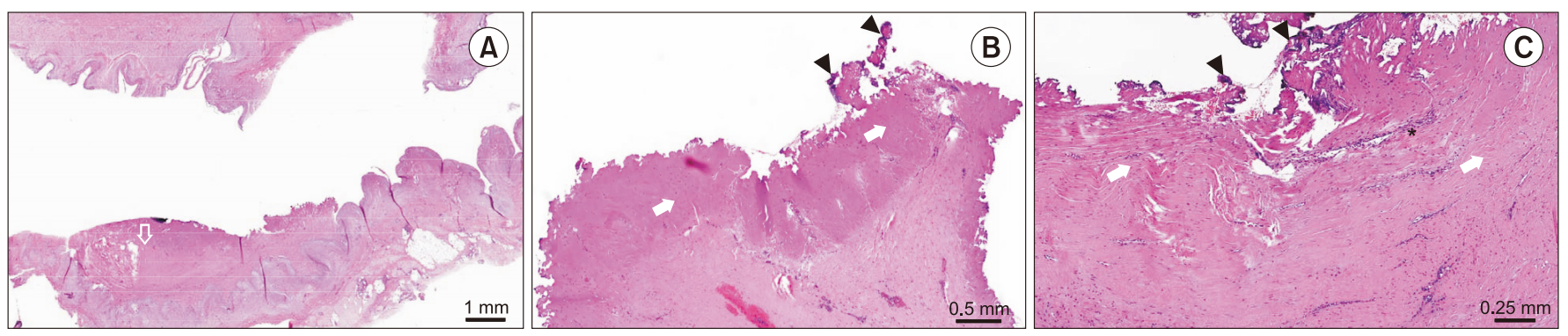

Figure 3. Pathological findings of peritoneal specimen after surgery. Hematoxylin and eosin (H\&E) staining demonstrated a thickened peritoneal membrane (empty arrow), with chronic inflammation (asterisk), fibrous tissue (white arrows), and dystrophied calcification (black arrowheads) in the peritoneal specimen. $(A) \times 40,(B) \times 100$, and $(C) \times 200$.

Table 3. Treatment outcomes of EPS patients

\begin{tabular}{|c|c|c|c|c|c|c|c|}
\hline Patient & $\begin{array}{c}\text { Medical treatment } \\
\text { before surgery }\end{array}$ & $\begin{array}{l}\text { Interval from } \\
\text { diagnosis of EPS to } \\
\text { surgery (mo) }\end{array}$ & $\begin{array}{l}\text { Survival duration } \\
\text { from the first } \\
\text { surgery (mo) }\end{array}$ & $\begin{array}{l}\text { Cause of } \\
\text { reoperation }\end{array}$ & $\begin{array}{l}\text { Time between } \\
\text { first and second } \\
\text { surgery }(\mathrm{mo})\end{array}$ & Outcome & $\begin{array}{l}\text { Cause } \\
\text { of death }\end{array}$ \\
\hline 1 & - & 1 & 0.3 & - & - & Death & Sepsis \\
\hline 2 & $\begin{array}{l}\text { Tamoxifen } \\
(20 \mathrm{mg} / \mathrm{d})\end{array}$ & 12 & 2 & - & - & Death & Sepsis \\
\hline 3 & - & 3 & 2.5 & - & - & Death & Sepsis \\
\hline 4 & - & 24 & 3 & - & - & Death & Sepsis \\
\hline 5 & - & 10 & 9 & - & - & Death & Sepsis \\
\hline 6 & $\begin{array}{l}\text { Tamoxifen } \\
(20 \mathrm{mg} / \mathrm{d})\end{array}$ & 8 & 2 & Small bowel perforation & 1.5 & $\begin{array}{l}\text { Reoperation/ } \\
\text { death }\end{array}$ & Sepsis \\
\hline 7 & $\begin{array}{l}\text { Tamoxifen } \\
(20 \mathrm{mg} / \mathrm{d})\end{array}$ & 1 & 5 & $\begin{array}{l}\text { Enterocutaneous and } \\
\text { internal fistula }\end{array}$ & 2 & $\begin{array}{l}\text { Reoperation/ } \\
\text { death }\end{array}$ & Sepsis \\
\hline 8 & - & 12 & 10 & $\begin{array}{l}\text { Small bowel obstruction/ } \\
\text { perforation }\end{array}$ & 2 & $\begin{array}{l}\text { Reoperation/ } \\
\text { death }\end{array}$ & Sepsis \\
\hline 9 & - & 0 & 22 & $\begin{array}{c}\text { Peritoneal abscess/ } \\
\text { bowel obstruction }\end{array}$ & 17 & $\begin{array}{l}\text { Reoperation/ } \\
\text { death }\end{array}$ & Sepsis \\
\hline 10 & - & 0 & 33 & Small bowel perforation & 32 & $\begin{array}{l}\text { Reoperation/ } \\
\text { death }\end{array}$ & Sepsis \\
\hline 11 & - & 7 & 24 & - & - & Alive & \\
\hline 12 & - & 10 & 123 & - & - & Alive & \\
\hline 13 & $\begin{array}{c}\text { Steroid, tamoxifen } \\
\text { (unknown dose) }\end{array}$ & 31 & 153 & - & - & Alive & \\
\hline
\end{tabular}

EPS, encapsulating peritoneal sclerosis; -, no medical treatment or no reoperation.

\section{Outcomes and prognostic factors associated with EPS}

Five patients died because of uncontrolled peritonitis and sepsis during postoperative care of the first surgery (Table 3). Eight patients survived after the first enterolysis. Median survival duration after the first surgery was 14 (1.3-27) months in the initial mortality group and 26.5 (6-184) months in the initial survivor group.

Five of eight survivors underwent reoperation for persistent peritonitis due to small bowel perforation (two patients), peritoneal obstruction and perforation (one patient), peritoneal abscess and small bowel obstruction (one patient), and enterocutaneous and internal fistula (one patient). Among these patients, cases 9 and 10 underwent adhesiolysis at the point of EPS diagnosis and survived for $>12$ months after the first surgery; however, they underwent colostomy for small bowel perforation or obstruction and finally died because of systemic infection. All five patients who underwent reoperation died. Meanwhile, three of eight patients who survived after the 
first surgery have survived without reoperation until now. Cases 12 and 13 survived for $>5$ years without any symptom, and case 11 survived for 2 years postoperatively. These three patients showed a good nutritional status on their last visit to the outpatient clinic.

The overall patient survival rate was $23.1 \%$. Median survival durations from EPS diagnosis was $22(1.3-184)$ months and that from the first surgery was $9(0.3-153)$ months. There were no significant differences in CT scan scores between the initial mortality and initial survivor groups after the first surgery. However, the CT scan scores were $<13$ in patients who survived for $>2$ years after the first surgery (cases 10-13). CT scan scores of three patients (case 11-13), who showed the best postoperative performance, were $\leq 10$, whereas the CT scan score of case 10, who maintained a relatively good performance for 30 months and died 32 months after the first surgery, was 12. Interestingly, all patients who survived for $>2$ years after the first surgery were males $<60$ years of age.

\section{Posttransplant EPS}

Three patients underwent kidney transplantation, and two of them were newly diagnosed with EPS posttransplantation. Case 11, a 38-year-old male with preserved renal function, showed the best outcome after enterolysis. In contrast, case 6 presented with severe EPS symptoms after graft failure and died of sepsis in the early phase after surgery. Case 7 with pre-existing EPS received surgical management after kidney transplantation because small bowel obstruction symptoms, including malnutrition, were aggravated and severe acute kidney injury developed. However, this patient developed enterocutaneous and internal fistulas without renal functional recovery after two successive surgeries and finally died because of sepsis.

\section{Discussion}

In this study, the overall survival rate of EPS patients was only $23.1 \%$, and median survival durations from EPS diagnosis and the first surgery were $22(1.3-184)$ and 9 (0.3-153) months, respectively. Therefore, advanced symptomatic EPS is difficult to treat by surgical management, and long-term survival ( $>5$ years) after surgical treatment remains poor regardless of the success of the first surgery. However, surgical intervention in the early phase of EPS may benefit young ( $<60$ years) male EPS patients with low CT scan scores $(<13)$.

Promisingly, the annual incidence of EPS is decreasing. A Dutch study reported a remarkable decrease in the annual incidence of EPS from $0.85 \%$ in 2009 to $0.14 \%$ in 2014 [22]. This decrease can be attributed to advances of PD techniques, use of physiological PD solutions (e.g., neutral solutions with low glucose degradation products), and availability of expert training to prevent peritonitis $[23,24]$. Nevertheless, EPS increasingly develops with prolonged PD duration. Although a high mortality rate due to irreversible EPS in patients undergoing PD has been reported with or without surgical intervention, in 2017, ISPD reported that there are insufficient data to withhold PD as the primary option of renal replacement therapy owing to the risk of EPS development.

In EPS management, developing a systemized protocol to detect and treat EPS in the early phase is important [25]. Tamoxifen with or without steroids in the early phase of EPS could be beneficial for inhibiting progression to severe EPS or recurrence [22,26].

Regarding the surgical treatment of EPS, total enterolysis relieves bowel obstruction in most EPS patients. However, enterolysis is time consuming, technically difficult, and prone to revisions and risks of various bowel complications; therefore, the surgical treatment of EPS is recommended only in patients refractory to medical treatment $[27,28]$. The mortality rate within 3 years after EPS diagnosis was $\sim 50 \%[6,22,29]$, and the EPS-related mortality rate 1 year after EPS diagnosis was $42 \%$ [6]. Consistent with our results, median survival was only 1 year after EPS diagnosis regardless of the treatment [29]. However, Kawanishi et al [19] and Ulmer et al [20] reported encouraging results with the surgical treatment of EPS in the late phase. In a Japanese study, overall mortality rates 1 and 3 years after EPS diagnosis were $7.7 \%$ and $22 \%$, respectively, and the median survival duration after EPS diagnosis was 43.9 months [19]. In a German study, the mortality rate within 1 year after surgery was $10 \%$ [20]. Kawanishi et al [30] recently reported longterm outcomes of the surgical treatment of EPS; in that report, all-cause mortality rate was $52.7 \%$, while the EPSrelated mortality rate was $25.1 \%$ after 24 years. Kawanishi et al $[28,30]$ performed total enterolysis with the noble plication of interintestinal suturing in order to prevent 
bowel kinking and re-obstruction due to adhesion, and this technique reduced the reoperation rate compared with enterolysis alone ( $12.3 \%$ vs. $30.4 \%$ ) [19]. Ulmer et al [20] performed peritonectomy and enterolysis in 26 EPS patients to prevent recurrent EPS. Compared with simple enterolysis, peritonectomy and enterolysis together reduced the reoperation rate to $10 \%$ and improved the 1-year survival rate by decapsulation and partial deserosation. In this study, five (38.4\%) patients died after the first surgery, showing poor outcomes similar to those reported in some previous studies $[6,22,29]$ but contrary to those reported by Kawanishi et al [19] and Ulmer et al [20]. The main cause of death in these five patients was recurrent or poorly controlled infection associated with small bowel perforation or severe intra-abdominal adhesion. Relatively worse outcomes in our series compared with those in Kawanishi et al's [30,31] study might be mainly attributed to the small study cohort and lack of cumulative experience of EPS surgical cases in our center. In contrast to the Japanese study in which postoperative perforation occurred in only eight $(3.2 \%)$ patients, microperforation events requiring urgent sealing during surgery, which were related to advanced bowel degeneration and severe adhesion, frequently occurred in our series. Therefore, we encountered more frequent infectionrelated complications postoperatively. Accumulation of more surgical cases and experience, application of more advanced surgical techniques, such as noble plication, and development of future novel techniques for EPS management at an earlier stage are expected to improve the surgical outcomes. Nevertheless, the current high mortality rate of EPS despite surgical treatment emphasizes the importance of adequate peritonitis treatment to prevent overt EPS development.

Peritoneal thickening and calcification, bowel wall thickening and dilatation, loculated ascites, and bowel tethering due to fibrosis are common and representative CT findings in advanced EPS. Previous studies have tried to correlate these categorized CT findings in EPS cases with disease severity, such as the need for enterolysis or prolonged total parenteral nutrition and death $[21,32,33]$. Although Tarzi et al [21] failed to show the screening benefits of CT for EPS diagnosis, their systemized CT scoring system could be beneficial for assessing the severity and prognosis of established EPS and determining the timing of surgical intervention. Kawanishi et al [30] also report- ed the benefits of using a CT scoring system to assess the prognosis of EPS, although they used a modified grading system. Our results that EPS patients who survived for $>2$ years achieved a low CT scan score $(<13)$ suggest that low CT scores in even advanced EPS cases can indicate surgical benefits.

In this study, three posttransplant EPS patients with a history of long-term PD were treated with surgical intervention; two patients were diagnosed with EPS posttransplantation and one developed EPS pretransplantation. The incidence rate of posttransplant EPS was $1 \%$ to $3 \%$ [13]. EPS usually develops in the early stage after kidney transplantation, which is supported by the twohit hypothesis of EPS pathogenesis [8]. Similar to our results, posttransplant EPS shows better prognosis and postoperative outcomes are favorable if renal function is preserved [22,34]. Moreover, clinical resolution of established EPS has been reported after kidney transplantation, possibly due to immunosuppression [35].

In summary, this was the first study to describe the surgical management of severe EPS in a single center in Korea. Despite a high mortality rate, clinical characteristics of and prognostic factors for enterolysis in advanced EPS patients in this study may provide baseline data for further studies on more advanced surgical management. Furthermore, we recommend timely surgical intervention in young symptomatic male EPS patients with relatively low CT scores.

\section{Conflicts of interest}

All authors have no conflicts of interest to declare.

\section{Authors' contributions}

Jung-Hwa Ryu, Kil-Yong Lee, and Tai Yeon Koo participated in data collection and manuscript writing. KookHwan Oh, Jaeseok Yang, and Kyu Joo Park participated in study design and data analysis and interpretation. Dong Ki Kim participated in the critical review of the study design and manuscript. All authors have read and approved the final manuscript.

\section{References}

[1] Blake PG. Integrated end-stage renal disease care: the role 
of peritoneal dialysis. Nephrol Dial Transplant 2001;16 Suppl 5:61-66.

[2] Schreiber MJ Jr. Changing landscape for peritoneal dialysis: optimizing utilization. Semin Dial 2017;30:149-157.

[3] Bradley JA, McWhinnie DL, Hamilton DN, et al. Sclerosing obstructive peritonitis after continuous ambulatory peritoneal dialysis. Lancet 1983;2:113-114.

[4] Gandhi VC, Humayun HM, Ing TS, et al. Sclerotic thickening of the peritoneal membrane in maintenance peritoneal dialysis patients. Arch Intern Med 1980;140:1201-1203.

[5] Kawaguchi Y, Kawanishi H, Mujais S, Topley N, Oreopoulos DG. Encapsulating peritoneal sclerosis: definition, etiology, diagnosis, and treatment. International Society for Peritoneal Dialysis Ad Hoc Committee on Ultrafiltration Management in Peritoneal Dialysis. Perit Dial Int 2000;20 Suppl 4:S43-S55.

[6] Brown EA, Van Biesen W, Finkelstein FO, et al.; ISPD Working. Length of time on peritoneal dialysis and encapsulating peritoneal sclerosis: position paper for ISPD. Perit Dial Int 2009;29:595-600.

[7] Honda K, Oda H. Pathology of encapsulating peritoneal sclerosis. Perit Dial Int 2005;25 Suppl 4:S19-S29.

[8] Kawanishi H, Kawaguchi Y, Fukui H, et al. Encapsulating peritoneal sclerosis in Japan: a prospective, controlled, multicenter study. Am J Kidney Dis 2004;44:729-737.

[9] Hong KD, Bae JH, Jang YJ, et al. Encapsulating peritoneal sclerosis: case series from a university center. Korean J Intern Med 2013;28:587-593.

[10] Kawanishi H, Moriishi M. Epidemiology of encapsulating peritoneal sclerosis in Japan. Perit Dial Int 2005;25 Suppl 4: S14-S18.

[11] Korte MR, Boeschoten EW, Betjes MG; EPS Registry. The Dutch EPS Registry: increasing the knowledge of encapsulating peritoneal sclerosis. Neth J Med 2009;67:359-362.

[12] Brown MC, Simpson K, Kerssens JJ, Mactier RA; Scottish Renal Registry. Encapsulating peritoneal sclerosis in the new millennium: a National Cohort Study. Clin J Am Soc Nephrol 2009;4:1222-1229.

[13] Johnson DW, Cho Y, Livingston BE, et al. Encapsulating peritoneal sclerosis: incidence, predictors, and outcomes. Kidney Int 2010;77:904-912.

[14] Alston H, Fan S, Nakayama M. Encapsulating peritoneal sclerosis. Semin Nephrol 2017;37:93-102.

[15] Braun N, Alscher DM, Fritz P, et al. Podoplanin-positive cells are a hallmark of encapsulating peritoneal sclerosis. Nephrol Dial Transplant 2011;26:1033-1041.
[16] Reimold FR, Braun N, Zsengellér ZK, et al. Transcriptional patterns in peritoneal tissue of encapsulating peritoneal sclerosis, a complication of chronic peritoneal dialysis. PLoS One 2013;8:e56389.

[17] Mori Y, Matsuo S, Sutoh H, Toriyama T, Kawahara H, Hotta $\mathrm{N}$. A case of a dialysis patient with sclerosing peritonitis successfully treated with corticosteroid therapy alone. Am J Kidney Dis 1997;30:275-278.

[18] Habib SM, Betjes MG, Fieren MW, et al.; EPS Registry. Management of encapsulating peritoneal sclerosis: a guideline on optimal and uniform treatment. Neth J Med 2011;69: 500-507.

[19] Kawanishi H, Shintaku S, Moriishi M, Dohi K, Tsuchiya S. Seventeen years' experience of surgical options for encapsulating peritoneal sclerosis. Adv Perit Dial 2011;27:53-58.

[20] Ulmer C, Braun N, Rieber F, et al. Efficacy and morbidity of surgical therapy in late-stage encapsulating peritoneal sclerosis. Surgery 2013;153:219-224.

[21] Tarzi RM, Lim A, Moser S, et al. Assessing the validity of an abdominal CT scoring system in the diagnosis of encapsulating peritoneal sclerosis. Clin J Am Soc Nephrol 2008;3: 1702-1710.

[22] Betjes MG, Habib SM, Boeschoten EW, et al. Significant decreasing incidence of encapsulating peritoneal sclerosis in the Dutch population of peritoneal dialysis patients. Perit Dial Int 2017;37:230-234.

[23] Brown EA, Bargman J, van Biesen W, et al. Length of time on peritoneal dialysis and encapsulating peritoneal sclerosis - position paper for ISPD: 2017 update. Perit Dial Int 2017;37:362-374.

[24] Nakayama M, Miyazaki M, Honda K, et al. Encapsulating peritoneal sclerosis in the era of a multi-disciplinary approach based on biocompatible solutions: the NEXT-PD study. Perit Dial Int 2014;34:766-774.

[25] Ti JP, Al-Aradi A, Conlon PJ, Lee MJ, Morrin MM. Imaging features of encapsulating peritoneal sclerosis in continuous ambulatory peritoneal dialysis patients. AJR Am J Roentgenol 2010;195:W50-W54.

[26] Lo WK, Kawanishi H. Encapsulating peritoneal sclerosis-medical and surgical treatment. Perit Dial Int 2009;29 Suppl 2:S211-S214.

[27] Célicout B, Levard H, Hay J, Msika S, Fingerhut A, Pelissier E. Sclerosing encapsulating peritonitis: early and late results of surgical management in 32 cases. French Associations for Surgical Research. Dig Surg 1998;15:697-702.

[28] Kawanishi H, Ide K, Yamashita M, et al. Surgical techniques 
for prevention of recurrence after total enterolysis in encapsulating peritoneal sclerosis. Adv Perit Dial 2008;24:5155.

[29] Balasubramaniam G, Brown EA, Davenport A, et al. The Pan-Thames EPS Study: treatment and outcomes of encapsulating peritoneal sclerosis. Nephrol Dial Transplant 2009; 24:3209-3215.

[30] Kawanishi H, Banshodani M, Yamashita M, Shintaku S, Dohi K. Surgical treatment for encapsulating peritoneal sclerosis: 24 years' experience. Perit Dial Int 2019;39:169174.

[31] Kawanishi H. Surgical and medical treatments of encapsulation peritoneal sclerosis. Contrib Nephrol 2012;177:38-47.

[32] Stafford-Johnson DB, Wilson TE, Francis IR, Swartz R. CT appearance of sclerosing peritonitis in patients on chronic ambulatory peritoneal dialysis. J Comput Assist Tomogr
1998;22:295-299.

[33] Krestin GP, Kacl G, Hauser M, Keusch G, Burger HR, Hoffmann R. Imaging diagnosis of sclerosing peritonitis and relation of radiologic signs to the extent of the disease. $A b$ dom Imaging 1995;20:414-420.

[34] Oguz EG, Okyay GU, Merhametsiz O, Ersoz S, Canbakan B, Ayli D. Long-term success with adhesiolysis in post-transplant encapsulating peritoneal sclerosis: a retrospective case series of 4 patients and review of the literature. Intern Med 2016;55:269-272.

[35] Hawley CM, Wall DR, Johnson DW, et al. Recovery of gastrointestinal function after renal transplantation in a patient with sclerosing peritonitis secondary to continuous ambulatory peritoneal dialysis. Am J Kidney Dis 1995;26: 658-661. 